\title{
LA NEGOCIACIÓN COLECTIVA CONJUNTA DE LOS EMPLEADOS PÚBLICOS EN EL ÁMBITO SUPRAMUNICIPAL: LA EXPERIENCIA DE LA ADMINISTRACIÓN LOCAL VASCA
}

\author{
Joint Collective Negotiation of Public Employees \\ in Local Institutions above Municipalities: \\ The Experience of the Basque Local Administration
}

\author{
M.a Nieves Martínez Gayoso \\ TEU de Derecho del Trabajo y de la Seguridad Social (UPV/EHU) \\ PRECO-CRL/LHK
}

\section{ABSTRACT}

Este articulo analiza la negociación colectiva conjunta para personal laboral y funcionarial al servicio de las Entidades Locales radicadas en la Comunidad Autónoma vasca, a raiz de la promulgación en 2015 de un texto refundido del Estatuto Básico de los Empleados Públicos y de la necesidad de desarrollar sus mandatos por parte de los poderes públicos vascos. Se compara la práctica con los mandatos legales y se analizan las propuestas barajadas en los anteproyectos de ley de empleo público vasco.

Palabras clave: negociación colectiva, Administración Pública, personal laboral, personal funcionarial, UDALHITZ. 
Artikulu hau Euskadiko Herri eta Tokiko Administrazioetan aurrera eramaten den negoziazio kolektiboa aztertzen du, kontuan izanik Herri Enplegatuen Oinarrizko Estatutua 2015 ean bateratu dela eta oinarrizko arauak garapenaren zain dagoela. Euskadiko Toki Administrazioetan aurrera eraman den praktika arauzko eta legezko aginduekin alderatzen da eta Euskadiko enplegu publikorako aurre proiektu legea aztertzen da ere.

Hitz gakoak: negoziazio kolektiboa, Herri Administrazioa, pertsonal laborala, funtzionarioak, UDALHITZ.

This article analyzes collective bargaining for labour and civil servants at the service of Local Authorities based in the Basque Autonomous Community, following the promulgation in 2015 of a revised text of the Basic Statute for Public Employees and the need to develop their mandates from the Basque public authorities. It compares the practice with the legal mandates and analyzes the proposals shuffled in the drafts of the Basque public employment law.

Keywords: Collective bargaining, Public Administration, workers, civil servants, UDALHITZ. 


\section{SUMARIO}

Sumario: 1. Introducción. 2. La negociación colectiva conjunta y para diferentes administraciones públicas antes del EBEP. 2.1. Reflexiones sobre la dualidad de regímenes laboral y funcionarial. 2.2. Los antecedentes normativos y jurisprudenciales del EBEP en materia de negociación colectiva conjunta. 3. La estructura de la negociación colectiva en las Administraciones públicas. 3.1. Las diferencias entre el ET y el EBEP. 3.1.1. Una breve reflexión sobre las unidades de negociación en el Estatuto de los trabajadores. 3.1.2. Las unidades de negociación en el Estatuto de los empleados públicos. 3.2. El concepto de mesas de negociación. 3.3. El ámbito supramunicipal y autonómico. 3.4. La preceptividad de la constitución de las mesas de negociación. 3.5. La constitución de mesas sectoriales en las entidades locales. 4. Las mesas de negociación en tanto comisiones negociadoras. 4.1. La problemática de la representación de la Administración pública en la negociación colectiva conjunta de personal laboral y funcionarial para las Entidades Locales y Forales radicadas en una Comunidad Autónoma. 4.2. La representación de los empleados públicos en la Mesa de Negociación para la negociación conjunta. 4.2.1. Delimitación conceptual: la capacidad y la legitimación negociadora. 4.2.1.1. La capacidad para negociar. 4.2.1.3. La legitimación inicial. 4.2.1.3. La legitimación plena 5. Las materias objeto de negociación en las Mesas. 5.1. Las materias objeto de negociación. 5.2. El contenido de los Pactos y Acuerdos. 6. Los acuerdos para la determinación conjunta de condiciones de trabajo de personal funcionario y laboral en el ámbito supralocal: naturaleza y eficacia jurídicas. 7. Conclusiones. 8. Bibliografía.

\section{Introducción}

El objeto de este artículo es el análisis del estado actual del marco jurídico de la negociación colectiva conjunta (para personal laboral y funcionarial) en el ámbito supramunicipal o para todas las Entidades Locales en una concreta Comunidad Autónoma, partiendo del ejemplo de la negociación desarrollada en las administraciones públicas locales vascas. Ese análisis ofrece una excelente ocasión para realizar un repaso general sobre conceptos básicos de la negociación colectiva en las administraciones públicas, aunque sin ánimo de exhaustividad dadas las limitaciones propias de un artículo doctrinal.

Las instituciones vascas optaron al poco tiempo de promulgarse la Constitución por la negociación colectiva conjunta ${ }^{1}$. Esta opción, así como el hecho de

${ }^{1}$ Decreto num. 83/1981, de 15 de julio, sobre regulación colectiva de las condiciones de trabajo de la Administración Local. El Anteproyecto de ley de empleo público insiste en esta misma línea para toda la negociación a desarrollar en las administraciones públicas de la CAV. 
adelantarse a los poderes normativos estatales en la regulación de estas materias, fue muy contestada y dio lugar a una también temprana sentencia del Tribunal Constitucional (en adelante, STC), la 57/1982, de 27 de julio².

Finalmente, la primera versión del EBEP- $2007^{3}$ se rinde a la realidad y, por un parte, trata de ofrecer un marco unitario a la regulación de las condiciones de trabajo de personas funcionarias públicas y personas trabajadoras por cuenta ajena al servicio de las Administraciones públicas y, por otra, ofrece amparo jurídico expreso a dos prácticas muy habituales que los poderes públicos estatales se habían resistido a reconocer hasta el momento en que se promulga el EBEP-2007: la legitimación de las asociaciones de municipios para negociar acuerdos cuyo ámbito de aplicación se extienda a varios municipios (art. 34.2) así como la negociación colectiva conjunta de personal laboral $\mathrm{y}$ funcionarial.

No obstante, el EBEP ${ }^{4}$ no resuelve todos los problemas que la dualidad de regímenes jurídicos funcionarios públicos y trabajadores por cuenta ajena presenta. Hay que tener en cuenta que se trata de una regulación básica pendiente o necesitada de desarrollo. Desgraciadamente, ese desarrollo, al menos por lo que a la actividad reguladora de los poderes públicos vascos se refiere, se está haciendo de rogar. Ello no es óbice para que la negociación colectiva se siga desarrollando, a lo que hay que añadir que existe un desarrollo de las bases, pero cronológicamente anterior al establecimiento de las mismas, de donde pueden surgir distorsiones. Todas estas son razones que justifican sobradamente el interés en analizar la situación actual de la negociación colectiva en las administraciones públicas vascas y el hecho de que el EBEP-2007 haya sufrido importantes cambios en su configuración esencial como consecuencia del cambio de gobierno y de las medidas anti crisis que se han ido sucediendo desde el año $2012^{5}$. La nueva versión del EBEP y el compromiso de los poderes públicos vascos de proceder a la actualización de la regulación del empleo público constituyen una ocasión ideal para tratar esta cuestión.

\footnotetext{
2 http://hj.tribunalconstitucional.es/HJ/es/Resolucion/Show/99\#complete_resolucion BOE núm. 197, de 18 de agosto de 1982.

${ }^{3}$ Ley 7/2007, de 12 de abril, Estatuto Básico del Empleado Público. En adelante, EBEP-2007.

${ }^{4}$ La versión actualmente vigente del EBEP es el Real Decreto Legislativo 5/2015, de 30 de octubre, por el que se aprueba el texto refundido de la Ley del Estatuto Básico del Empleado Público (en adelante, EBEP).

5 La clave está en el Real Decreto-ley 20/2012, de 13 de julio, de medidas para garantizar la estabilidad presupuestaria y de fomento de la competitividad.
} 


\section{La negociación colectiva conjunta y para diferentes administraciones públicas antes del EBEP}

Durante mucho tiempo, el ordenamiento jurídico español ha partido de la premisa de que funcionarios públicos y trabajadores al servicio de las Administraciones públicas eran titulares de estatutos jurídicos diferentes, tanto por lo que respecta a su relación individual de trabajo y empleo, como en lo relativo a sus relaciones colectivas y sindicales. El EBEP-2007 trata de acortar distancias entre ambos estatutos, pero resulta significativa, por el tema que ahora nos concierne que es la negociación colectiva, que el artículo $32 \mathrm{EBEP}$ insista en que «la negociación colectiva de los empleados públicos con contrato laboral se regirá por la legislación laboral, sin perjuicio de los preceptos de este capitulo que expresamente les son de aplicación». Las diferencias de regulación se mantienen y aunque el EBEP tiene buenas intenciones, no logra resolver todos los problemas derivados de ello.

\subsection{Reflexiones sobre la dualidad de regímenes laboral y funcionarial}

La primera cuestión a subrayar parte del diferente régimen de distribución de competencias entre el Estado y las Comunidades Autónomas sobre la legislación laboral y sobre el régimen estatutario de los funcionarios públicos.

El art. 149.1.7 de la Constitución Española (en adelante, CE) proclama la competencia exclusiva del Estado sobre la legislación laboral, lo cual según la interpretación mayoritaria implica la falta de competencia normativa de las Comunidades Autónomas sobre la materia laboral, incluida, por supuesto, la negociación colectiva.

Por el contrario, el art. 149.1.18 CE establece una distribución de competencias más compleja por lo que respecta al régimen estatutario de los funcionarios públicos, al proclamar la competencia exclusiva del Estado sobre las bases de dicho régimen y reconocer competencias normativas de desarrollo de las bases a las Comunidades Autónomas. Simplificando mucho las cosas, a las Cortes Generales no sólo les compete dictar las bases del estatuto de los funcionarios públicos, sino que les compete, asimismo, la regulación completa del estatuto de los funcionarios de la Administración General del Estado. Las Comunidades Autónomas, por su parte, tienen competencia para el desarrollo de las bases y, por lo tanto, para regular el estatuto completo de sus funcionarios, sin perjuicio de respetar dichas bases.

Como dice Jiménez (2004), la particularidad de esta atribución de competencias reside en la necesidad de diferenciar entre las bases del régimen estatutario de los funcionarios de las Administraciones públicas y el régimen estatutario de los funcionarios de la Administración General del Estado. Los poderes 
normativos del Estado (central), insisto, disponen en esta materia de una competencia completa de desarrollo, como consecuencia de tener que dotar de un régimen jurídico a su propia burocracia y así los problemas no tardan en llegar cuando las Cortes Generales utilizan como técnica legislativa aquella que consiste en extraer las bases del régimen estatutario de los funcionarios públicos de la regulación pensada para su propia burocracia. Como dice Jiménez (2004)

la legislación de la función pública de ámbito estatal pretende proporcionar soluciones para resolver problemas de su propia burocracia; en ocasiones, la confusión entre el estatuto básico y el propio de los funcionarios de la Administración General del Estado determina que se exporten esos problemas (y no sus soluciones) a otros contextos organizativos como las CCAA o las EELL.

Esta técnica, además de generar un marco jurídico confuso, provoca que algunas soluciones pensadas para problemas específicos de la Administración General del Estado, acaben creando nuevos problemas al insertarse en una organización ajena a los mismos, además de dejar sin resolver los específicos de cada ámbito.

En fin, de acuerdo a la propia remisión a la legislación laboral que efectúa el artículo 32.1 EBEP, las reglas esenciales sobre la negociación colectiva de los trabajadores de las Administraciones públicas se encuentran en el Estatuto de los Trabajadores (en adelante, ET). El artículo $37 \mathrm{CE}$ ordena a la ley garantizar el derecho a la negociación colectiva, así como la fuerza vinculante de los convenios y de acuerdo con ello, una de las principales finalidades que se plantea el ET a la hora de abordar la negociación colectiva laboral consiste en garantizar un convenio colectivo de eficacia jurídica normativa y personal general. Este convenio colectivo es el eje sobre el que gira el entero sistema de negociación colectiva del ET. La principal preocupación del Título III del ET consiste, por lo tanto, en generar garantías de esa fuerza vinculante del convenio, lo cual trata de lograrse mediante una atención exhaustiva al ámbito en que se va a desarrollar la negociación colectiva y a la selección del interlocutor válido en dicho ámbito. Asimismo, cobra especial importancia la tramitación del acuerdo una vez que se ha producido.

Las leyes de función pública, a diferencia del ET, tratan de asegurar que la Administración someta sus decisiones a las representaciones sindicales de sus empleados, pero sin que ello paralice la actividad administrativa. El resultado es una regulación que impone cauces formales e institucionalizados de diálogo, pero que presta escasa atención a la articulación del resultado de esa negociación con el sistema de fuentes del régimen estatutario de los funcionarios públicos, así como a las consecuencias (jurídicas) derivadas del desconocimiento por parte de la Administración de sus deberes de negociación. El eje de la regulación no es el convenio (denominado Pacto o Acuerdo) sino la Mesa de Negociación. 


\subsection{Los antecedentes normativos y jurisprudenciales del EBEP en materia de negociación colectiva conjunta}

Los antecedentes normativos del EBEP (como la versión original de la LORAP $^{6}$ y el ET) no establecían expresamente la posibilidad de negociación colectiva conjunta, lo cual había dado lugar a pronunciamientos judiciales constantes que negaban la validez para los funcionarios públicos de los acuerdos que pretendían determinar conjuntamente con los trabajadores sus condiciones de trabajo. Por todas, la Sentencia del Tribunal Supremo, sala de lo contenciosoadministrativo, de 22 de octubre de 1993 (rec. núm. 4367/1990), pone de manifiesto buena parte de los problemas que la ausencia de regulación y la dualidad de regímenes plantean:

F.D. 4: ...la peculiaridad de un pacto aplicable globalmente a un colectivo que está sujeto a sendos ordenamientos sustantivos netamente diferenciados, sugiere la previa interrogación acerca de la normalidad jurídica de este fenómeno...

F.D. 5: ...lo que debe ahora dilucidarse consiste en determinar si los respectivos ordenamientos de la negociación colectiva (el de las relaciones estatutarias de los funcionarios públicos y el de las relaciones laborales de los trabajadores) ofrecen entre sí el grado de permeabilidad suficiente para posibilitar una negociación y eventual regulación unitaria bajo forma contractual, y para ello deben ponerse en relación los componentes básicos de los respectivos sistemas.

F.D. 6: Siguiendo el orden de los factores anteriormente enumerados corresponde hacer aquí las siguientes precisiones:

a) la estructura orgánica representativa integrada en la Mesa de Negociación, a que se refiere el art. 31.2 de la Ley $9 / 1987$, no es coincidente con la prevista en el art. 87.1 de la Ley 8/1980 para la constitución de la comisión negociadora;

b) el grado de autonomía de la negociación colectiva de los funcionarios, resultante de los arts. 32 y 35 de la Ley 9/1987, es manifiestamente más limitado que el reconocido a los trabajadores en el art. 85 de la Ley 8/1980;

c) la situación de supremacía de una de las partes, reflejada en el art. 35 de la Ley $9 / 1987$ —al requerir la validez y eficacia de los pactos y acuerdos negociados la aprobación expresa y formal del Pleno de la Entidad Local respectiva一, no tiene correlación en la letra de los arts. 82 y 90.2 de la Ley 8/1980, aplicables inclusive cuando el empresario sea la Entidad pública;

d) la misma diferencia de régimen jurídico se observa —en el supuesto de fracaso de la negociación-, entre lo establecido en el art. 37.2 de la Ley 9/1987 y la regulación que deriva del Título II del RDLey 17/1977, de 4 de marzo, y la STC 11/1981, de 8 de abril;

e) igualmente, es notoria la diferencia en las reclamaciones jurisdiccionales relativa a esta materia, reservadas al orden contencioso-administrativo tra-

${ }^{6}$ Ley 9/1987, de 12 de junio de Órganos de Representación, determinación de las condiciones de trabajo y participación del personal al servicio de las Administraciones Públicas (en adelante, LORAP). 
tándose de funcionarios, en tanto es competencia del orden social cuando conciernen al personal laboral, sea pública o privada la unidad empleadora (arts. 9.5 y 25 LOPJ).

La trascendencia de las citadas contradicciones, ponen de manifiesto la inviabilidad de una articulación unitaria del pacto que abarque conjuntamente a los funcionarios y al personal laboral cuyo primer escollo, como hemos dicho, se manifiesta en la dualidad de instancias jurisdiccionales en concurrencia.. Procede, por tanto, la declaración de nulidad...

Con anterioridad al EBEP ya se habían dictado normas que reconocían expresamente la oportunidad y la necesidad de la negociación colectiva conjunta. Con posterioridad a la anulación por el TC del Decreto núm. 83/191, de 15 de julio del Gobierno Vasco, la versión inicial del Decreto del Gobierno Vasco 304/1987, de 6 de octubre, de Órganos de Representación, regulación del proceso electoral, determinación de las condiciones de trabajo y participación del personal al servicio de las Administraciones públicas de la Comunidad Autónoma del País Vasco (en adelante, DGVORAP), no incluía referencias a la negociación colectiva conjunta. Sin embargo, el Decreto del Gobierno Vasco 228/1990, de 4 de septiembre reformó varios de sus artículos y regula la constitución de comisiones negociadoras de ámbito supramunicipal para la determinación conjunta de materias y condiciones de trabajo para el personal laboral y funcionarial al servicio de las entidades locales de la Comunidad Autónoma vasca.

Según el art. 17.1 DGVORAP7 (redactado conforme al Decreto del Gobierno Vasco 228/1990, de 4 de septiembre):

Se constituirá una Mesa General de Negociación en el ámbito de la Administración de la Comunidad Autónoma del País Vasco, así como en las Entidades Forales y Locales del País Vasco, que serán competentes para determinar las condiciones de trabajo de los funcionarios públicos del ámbito correspondiente.

Asimismo, podrá constituirse, previo acuerdo alcanzado por los órganos competentes de las Administraciones Públicas Vascas, y de las Organizaciones Sindicales más representativas a nivel estatal y de Comunidad Autónoma, así como de los Sindicatos que hayan obtenido el $10 \%$ o más de los representantes en las Elecciones para Delegados y Juntas de Personal, una Mesa de Negociación para la determinación conjunta de las retribuciones y condiciones de trabajo de los empleados públicos al servicio de diferentes Administraciones Públicas Vascas.

Esta previsión no hace sino ajustar la norma a la realidad y recoger normativamente una práctica habitual en las administraciones públicas en general y en

\footnotetext{
7 Insisto redactado conforme al Decreto del Gobierno Vasco 228/1990, de 4 de septiembre.
} 
las vascas en particular. Sin embargo, hay que reconocer que su amparo legal es un tanto endeble, hasta que se promulga el EBEP-2007, comenzando por poner de manifiesto lo poco coherente que resulta el art. 17 DGVORAP con su propio ámbito de aplicación, definido en su artículo 1.2, según el cual:

Quedan excluidos del presente Decreto: a) Los miembros de la Policía de la Comunidad Autónoma de Euskadi y b) el personal laboral al servicio de las Administraciones públicas de la Comunidad Autónoma Vasca que se someterán a la legislación laboral.

Asimismo, meses antes de la promulgación del EBEP y haciéndose eco de las críticas que había recibido la regulación entonces vigente en materia de negociación colectiva en las Administraciones públicas, la Ley 21/2006 de reforma de la Ley 9/1987, de órganos de representación, determinación de las condiciones de trabajo y participación del personal al servicio de las Administraciones públicas introdujo el concepto de mesas para la negociación de las bases de los estatutos de los empleados públicos y del incremento global de las retribuciones a incluir en los Presupuestos Generales del Estado así como las mesas para la negociación de materias y condiciones de trabajo conjuntas para personal funcionarial y laboral ${ }^{8}$.

Pero ni esas normas ni el propio EBEP resuelven de forma eficaz los problemas que plantea su articulación? 9 Por ello, en el presente artículo, haré especial hincapié en el concepto de las mesas de negociación y sus funciones tanto para delimitar la estructura de la negociación colectiva de los empleados públicos, como su función de comisiones negociadoras ${ }^{10}$. Analizaremos el ámbito material de la negociación colectiva conjunta y la naturaleza jurídica y eficacia de los pactos y acuerdos y dejaremos para mejor ocasión, las cuestiones relativas a su impugnación, que siguen siendo una cuestión abierta como bien pone de manifiesto Roqueta (2008: 9-11), así como las cuestiones vinculadas a las consecuencias del fracaso en la negociación.

\section{La estructura de la negociación colectiva en las Administraciones públicas}

Las ideas fuerza sobre las que pivota este epígrafe son las siguientes:

En primer lugar, la diferencia de regulación entre el ET y el EBEP en esta materia.

8 Vid Marín (2006).

9 Para un análisis en profundidad de estas cuestiones vid. Marín (1999).

${ }^{10}$ La doctrina coincide en señalar esta doble función de las mesas de negociación. Por todos, Del Rey (1988: 180-181), Roqueta (1996: 108) y Fernández y Rodríguez (1996: 33). 
En segundo lugar, y estrechamente relacionado con lo anterior, las unidades de negociación predeterminadas por las leyes para el empleo público no se ajustan bien a las reglas del ET en materia de negociación colectiva, lo cual genera disfunciones que, a raíz del reconocimiento legal expreso por el EBEP de la negociación colectiva conjunta y de ámbito supramunicipal, aparecen en parte corregidas, pero que merecen un comentario.

En tercer lugar, el EBEP guarda silencio sobre las relaciones que cabe entablar entre las diferentes unidades de negociación o Mesas de Negociación, se mejoran considerablemente los problemas que planteaba la LORAP, pero siguen existiendo importantes lagunas, en parte corregidas, como veremos, a través del establecimiento de principios ordenadores de la negociación colectiva (funcionarial y extensibles a la laboral) y que merecen un tratamiento.

En cuarto lugar, se va a hacer hincapié sobre otros dos temas: la constitución de mesas sectoriales en las entidades locales y la relación entre autonomía local y constitución preceptiva de comisiones negociadoras y/o su eventual «sustitución» por las mesas supra locales.

\subsection{Las diferencias entre el ET y el EBEP}

El ET organiza la estructura de la negociación colectiva sobre el concepto de las unidades de negociación, que podemos definir como el conjunto de trabajadores y empresarios para los que se negocia ${ }^{11}$. Las unidades de negociación son una realidad preexistente a la negociación colectiva ${ }^{12}$, que condiciona tanto el ámbito de aplicación del convenio producto de la negociación, como la selección de los sujetos encargados de representar a los colectivos citados en dicha negociación.

Los problemas surgen cuando la ley no tiene en cuenta que las unidades de negociación son realidades preexistentes a la norma y decide intervenir sobre esa realidad sin respetarla. Esta opción tiene como resultado una predeterminación legal de las unidades de negociación con un alto grado de artificialidad que suele desembocar en conflictos de difícil solución desde parámetros jurídicos.

\subsubsection{Una breve reflexión sobre las unidades de negociación en el Estatuto de los Trabajadores}

A pesar de que en apariencia el Estatuto de los Trabajadores reconoce la plena libertad de los negociadores para decidir el ámbito de aplicación del con-

11 Alonso y Casas (2002: 831): «El conjunto de trabajadores y empresarios para los que se negocia forma la unidad de negociación, que preexiste a la negociación y, por ello, al convenio que de ella resulte. El convenio colectivo eventualmente conseguido tiene un ámbito de aplicación posterior a su celebración, necesariamente coextenso con la unidad de negociación para la que se ha celebrado."

12 Por todos, Roqueta (1996: 115). 
venio, lo cierto es que el ET articula su sistema de negociación en torno a los ámbitos de constitución y actuación de los delegados de personal y Comités de Empresa, que a su vez giran sobre los conceptos de empresa o centro de trabajo, todo lo cual casa mal con la compleja estructura de las Administraciones públicas. La opción legal para la negociación colectiva funcionarial de abarcar tanto a las Administraciones Territoriales como a sus organismos autónomos no se amolda bien a las unidades de negociación definidas en el ET, de tal manera que no resulta fácil determinar si un convenio colectivo negociado por una Administración pública tiene ámbito empresarial, superior a la empresa o inferior a la empresa y la concreción de este dato es esencial para determinar si la comisión negociadora se ha constituido debidamente o no. Algunos ejemplos de unidades de negociación conflictivas serían las siguientes: a) la unidad de negociación constituida por todos los trabajadores de una Administración territorial cualquiera y sus organismos autónomos; b) la unidad de negociación constituida por todos los trabajadores de las Entidades Locales ubicadas en el territorio de una determinada Comunidad Autónoma (en términos laborales diríamos que se trata de una unidad de ámbito superior a la empresa y a efectos de este artículo la vamos a denominar como unidad supramunicipal); c) la unidad de negociación constituida por todas las Universidades públicas ubicadas en el territorio de una determinada Comunidad Autónoma ${ }^{13}$.

Centrándonos en el supuesto conflictivo que constituye el objeto principal de este artículo, respecto de la unidad de negociación constituida por todos los trabajadores de las Entidades Locales ubicadas en una concreta Comunidad Autónoma, desde la perspectiva laboral, no hay problemas en reconocer que se trata de un ámbito superior a la empresa. Antes de la promulgación del EBEP-2007, el problema radicaba en las dificultades para instrumentar la representación de una pluralidad de entidades locales, ante la ausencia de asociaciones empresariales legitimadas para la negociación. De ahí la importancia de que el EBEP proclame la legitimación negocial de las asociaciones de municipios $^{14}$. Este artículo 34.2 EBEP debería constituir uno de los preceptos del EBEP que expresamente le es de aplicación a la negociación colectiva de los empleados públicos con contrato laboral.

13 Vid. STS, sala de lo social, de 17 de febrero de 2017, n. ${ }^{\circ} 140 / 2017$, recurso n. ${ }^{\circ} 112 / 2016$ y que trata sobre la articulación entre la negociación desarrollada en el ámbito que engloba al conjunto de las Universidades públicas de Cataluña y el convenio colectivo para el personal laboral de la Universidad de Barcelona, respecto del personal de administración y servicios.

14 Art. 34.2 EBEP: 2. "Se reconoce la legitimación negocial de las asociaciones de municipios, asi como la de las Entidades Locales de ámbito supramunicipal. A tales efectos, los municipios podrán adherirse con carácter previo o de manera sucesiva a la negociación colectiva que se lleve a cabo en el ámbito correspondiente». En sentido crítico con esta opción Mauri (2008: 402-403). 


\subsubsection{Las unidades de negociación en el Estatuto de los empleados públicos}

Tanto su antecesora, la LORAP ${ }^{15}$, como el EBEP optan por una definición legal de las unidades de negociación para los funcionarios públicos, que reciben el nombre de Mesas de Negociación y que toman como referencia para su definición las Administraciones Territoriales y los Organismos Autónomos adscritos a ellas. Es decir, toman una referencia muy diferente a la del ET.

El EBEP establece imperativamente la constitución de una serie de Mesas generales de Negociación, competentes para la determinación de las condiciones de trabajo de los empleados (art. 36.3) y de los funcionarios públicos (art. 33) del ámbito correspondiente.

Una de las críticas que se hacía a la regulación de la LORAP en torno a la mesas de negociación era que no se refería a las relaciones que, en su caso, cabía entablar entre las diferentes Mesas de Negociación (la de la Administración del Estado, las de cada una de las Comunidades Autónomas, y cada una de las Entidades Locales). El otro gran problema de la LORAP es que era un ejemplo paradigmático de legislación confusa al incluir en un único texto las bases del estatuto de los funcionarios públicos junto con el desarrollo de esas bases para la Administración General del Estado.

El EBEP avanza considerablemente en este sentido, al diferenciar, por una parte, la unidad de negociación encargada de sentar las bases de estatuto de los empleados públicos, entre las que se incluye la negociación del incremento global de las retribuciones del personal al servicio de las Administraciones públicas que corresponda incluir en el Proyecto de Ley de Presupuestos Generales del Estado de cada año (art. $36 \mathrm{EBEP}$ ); y, por otra parte, las unidades de negociación constituidas por los funcionarios públicos (art. 34 EBEP) y por el personal funcionario, estatutario y laboral (art. 36.3 EBEP) de cada una de las Administraciones territoriales y sus respectivos organismos autónomos ${ }^{16}$. Aunque sigue habiendo un número excesivo de mesas de negociación, al menos el régimen de competencias entre ellas queda más claro.

15 La disposición derogatoria única del EBEP deroga la LORAP, excepto su artículo 7 (relativo a las unidades electorales para la constitución de Juntas de Personal) y con la excepción contemplada en la disposición transitoria quinta en relación con el procedimiento electoral general. A ello hay que añadir que esta ley queda derogada con el alcance previsto en el apartado 2 de la disposición final cuarta, según la cual «hasta que se dicten las leyes de Función Pública y las normas reglamentarias de desarrollo se mantendrán en vigor en cada Administración Pública las normas vigentes sobre ordenación, planificación y gestión de recursos humanos en tanto no se opongan a lo establecido en este Estatuto", luego la regulación de la LORAP en torno a las mesas de negociación a constituir en el ámbito de la Administración general del estado, en tanto normativa no básica sino reguladora del específico régimen estatutario de los funcionarios públicos de la Administración General del Estado, siguen en vigor hasta que se dicte la ley de función pública correspondiente que venga a sustituirla.

16 Esta opción, como ya he señalado antes, se avanza en la Ley 21/2006, de reforma de la LORAP. 
Asimismo, el EBEP establece principios a los que se sujeta la negociación colectiva de los empleados públicos (art. 33) y que, indirectamente, determinan o condicionan las relaciones entre las diferentes unidades de negociación, como los principios de legalidad, de cobertura presupuestaria (art. 33.1) y el principio de competencia que se enuncia entre otros en el artículo 37.1 al indicar que «serán objeto de negociación, en su ámbito respectivo y en relación con las competencias de cada Administración pública y con el alcance que legalmente proceda en cada caso, las materias siguientes..."

Una interpretación literal de la ley conduciría a afirmar que en ningún caso existirá un solapamiento entre los acuerdos adoptados por las diferentes Mesas de Negociación, ya que cada una de ellas es competente para la determinación de las condiciones de trabajo de los funcionarios y empleados públicos del ámbito correspondiente. Es decir, la Mesa General de la Administración del Estado negociaría exclusivamente las condiciones de trabajo de los funcionarios públicos de la Administración del Estado y no de las Comunidades Autónomas y Entidades Locales. Igualmente, la Mesa General de cada Entidad Local negociaría las condiciones de trabajo de sus funcionarios y empleados públicos, sin preocuparse por la negociación desarrollada en otros ámbitos.

Sin embargo, la centralización de la negociación colectiva de los empleados públicos no se manifiesta únicamente dentro de cada Administración territorial entre las respectivas Mesas generales y las mesas sectoriales, sino que se pone, asimismo, de manifiesto en la referencia del EBEP a que las materias que enuncia serán objeto de negociación "en relación con las competencias de cada Administración pública». La negociación y, en su caso, los acuerdos alcanzados en la Mesa para las materias susceptibles de regulación estatal con carácter de norma básica, vinculará la negociación a desarrollar por las Mesas Generales de las administraciones de las Comunidades Autónomas y Entidades Locales, «sin perjuicio de los acuerdos a que puedan llegar las Comunidades Autónomas en su correspondiente ámbito territorial en virtud de sus competencias exclusivas y compartidas en materia de Función Pública» (art. 36.1 EBEP). En fin, como indica el TS (F.D. 7, Ar. 1993/7544)

El marco de contractualidad, por tanto, está en correlación con el contenido de las potestades normativas y de autoorganización del órgano administrativo correspondiente (en el caso de la Administración local del Pleno del ayuntamiento o de las entidades locales)...

Por lo tanto, el solapamiento entre la negociación desarrollada por las diferentes unidades de negociación se produce y en la misma línea ahonda el hecho de que al TC no le cabe duda de que, como consecuencia de la vinculación de la legislación de las Comunidades Autónomas a los topes máximos de las retribuciones decididos por la LPGE (principio de legalidad y de cobertura presupues- 
taria de la negociación colectiva), el incremento acordado en la Mesa General de la Administración General del Estado (art. 31.1 LORAP), cuando trascienda a la LPGE, vinculará a las negociaciones desarrolladas en todas las Administraciones públicas (ver F.J. 5. ${ }^{\circ}$ STC 24/2002).

A todo ello hay que añadir cierta pereza o indolencia de los órganos legislativos autonómicos a la hora de proceder al desarrollo de las bases, indolencia de la que la Administración General del Estado no suele contagiarse y que provoca que esa regulación completa y detallada, pensada para una burocracia concreta, se acabe extendiendo a las de las comunidades autónomas y entidades locales. El EBEP se hace eco, hasta cierto punto de este fenómeno, a mi entender, al permitir o prever expresamente la posibilidad de que una Administración o Entidad Pública (cualquiera) pueda adherirse a los acuerdos alcanzados dentro del territorio de cada Comunidad Autónoma, opción que puede resultar muy interesante, por ejemplo, para que los entes locales se adhieran a los acuerdos reguladores alcanzados por las administraciones de comunidades autónomas de carácter uniprovincial. Tal y como está redactado el precepto no parece que esté pensando en que la administración de una comunidad autónoma se adhiera a los acuerdos negociados en otra o en la administración general del estado, pero lo que no parece dudoso es que no es preciso que el acuerdo al que se pretenda adherir una Administración o Entidad Pública prevea expresamente un mecanismo concreto de adhesión o la posibilidad de la misma, sino que queda en mano de cada Entidad la toma de esa decisión de adhesión a lo negociado en otro ámbito o unidad.

\subsection{El concepto de mesas de negociación}

Ya he señalado que en la regulación legal de la negociación colectiva de los empleados públicos el eje del sistema de negociación colectiva no es el convenio colectivo, como en el ET, sino las Mesas de Negociación, lo cual se debe, en mi opinión, a las reticencias para reconocer sin ambages la fuerza vinculante de los productos de esta negociación colectiva, sobre la base de la reserva de ley que impone la Constitución sobre el estatuto de los funcionarios públicos.

El carácter de las mesas de negociación como órganos institucionalizados y permanentes de diálogo más que como comisiones negociadoras que se constituyen para procesos que tienden a tratar de alcanzar un acuerdo (convenio colectivo) y que se diluyen una vez alcanzado el mismo, se constata claramente en la previsión del artículo 35.2 EBEP, según el cual

las variaciones en la representatividad sindical, a efectos de modificación en la las mesas de negociación, serán acreditadas por las organizaciones sindicales interesadas, mediante el correspondiente certificado de la oficina pública de registro competente, cada dos ańos a partir de la fecha inicial de constitución de las citadas mesas. 
Por otro lado, la actual regulación del EBEP desvirtúa absolutamente la fuerza vinculante de lo acordado en el seno de las mesas de negociación, tanto para funcionarios como para laborales. El EBEP ha resuelto los problemas que la sala de lo contencioso administrativo del Tribunal Supremo manifestaba en torno a la situación de supremacía que ostenta la Administración pública en la negociación colectiva funcionarial y que, en su opinión, no tenía correlación en la regulación del ET sobre la negociación colectiva laboral. El EBEP ha homogeneizado ambos estatutos para los empleados públicos y ha proclamado la supremacía de la Administración pública también en la negociación para los empleados públicos con contrato laboral.

El artículo 33.1 EBEP menciona entre los principios ordenadores de la negociación colectiva de los funcionarios públicos los de legalidad y cobertura presupuestaria. Principios que, obviamente, son, asimismo, predicables de la negociación colectiva del personal laboral al servicio de las administraciones públicas ${ }^{17}$. Como he tenido ocasión de explicar en otras ocasiones con profusión, tradicionalmente la reserva a la ley sobre el estatuto de los funcionarios públicos $^{18}$ (art. 103.3 CE) se ha interpretado como un límite a la negociación colectiva, sin tener en cuenta que el reconocimiento de derechos sindicales a los funcionarios públicos implica, a su vez, la reserva de un espacio de actuación propio y suficiente a la negociación colectiva en dicho ámbito (art. 28.1 CE). La reserva a la ley, se transforma en la reserva a la norma pública ${ }^{19}$, reduciendo considerablemente el espacio posible de desarrollo de la negociación colectiva.

El principio de legalidad en la Administración pública, en tanto principio constitucional, parte de la necesidad de imponer al poder legislativo la obligación de limitar la discrecionalidad administrativa, lo cual dota a la ley de un papel especialmente preponderante en la definición del estatuto de los funcionarios públicos que puede interpretarse en el sentido de que la ley tenga la obligación, en todo caso, de fijar un régimen de salvaguarda que pueda regir en defecto de acuerdo en la negociación colectiva y que sirva, asimismo, de límite a la innovación normativa por parte de la potestad reglamentaria, pero no implica necesariamente que

17 Así lo ha entendido y puesto de manifiesto el anteproyecto de ley de empleo público elaborado por el Gobierno Vasco (en adelante, APLEP); vid. art. 196.

${ }_{18}$ Una parte de la doctrina niega la posibilidad de intervención de la negociación colectiva en las materias reservadas a la ley, por ejemplo, Montoro (1995: 196). A mi me parece más correcto entender que lo que queda vedado a la intervención de la negociación colectiva no es la materia objeto de reserva de ley, sino la materia objeto de regulación imperativa por parte de ella. Ver, por todos, Cantero (2001: 329).

19 Orsi (1993: 464-465) se muestra partidario de diferenciar la reserva a la ley de la reserva a la norma pública, sin confundirlas ya que dicha confusión tiene como consecuencia la exclusión de la negociación colectiva. 
...las características de pormenorización, rigidez y uniformidad inherentes al régimen estatutario emanado de la legislación del estado y, en su caso, de los órganos legislativos de las comunidades autónomas, no permiten que por analogía con el sistema de relaciones laborales tal bloque legislativo sea identificable como plataforma de «mínimos», sobre la que pueda pivotar una constelación de unidades negociadoras ... (F.J. 3. ${ }^{\circ}$ de la STS, S. 3. ${ }^{\text {a }}$, de 4 de diciembre de 1995 [AL núm. 24/1996, p. 1903] ${ }^{20}$ ).

He llegado a defender que semejante lectura está absolutamente desfasada, es anticonstitucional por negar espacio suficiente a la negociación colectiva como facultad inescindible respecto de la libertad sindical y es un claro ejemplo de la confusión denunciada por Orsi Bataglini entre reserva de ley y reserva a la norma pública. El EBEP-2007, por fin, así lo entendió y procedió al establecimiento de amplios espacios para la intervención de la negociación colectiva en áreas importantes como los permisos ${ }^{21}$ (arts. 48 y 49) y las vacaciones (art. 50), espacios de colaboración normativa que se fueron al garete con las reformas vinculadas a la contención del gasto y del déficit público y que brillan por su ausencia en la actual configuración del EBEP-2015.

El EBEP, a diferencia de su antecesora, regula las cuestiones vinculadas a la negociación (y ulterior acuerdo) sobre materias a incluir en normas con rango de ley, refiriéndose al hecho de que «su contenido carecerá de eficacia directa» (art. 38.3), si bien el órgano de gobierno respectivo que tenga iniciativa legislativa procederá a la elaboración del correspondiente proyecto de ley «conforme al contenido del Acuerdo y en el plazo que se hubiera acordado», estableciéndose reglas concretas para el supuesto de que finalmente lo acordado no se incorpore en el proyecto de ley o no sea aprobado por el órgano legislativo correspondiente. Todo ello constituye un gran avance, si bien se ha optado por una regulación muy suave de las consecuencias aparejadas a la falta de incorporación de lo acordado a los textos legislativos correspondientes. Se gana en seguridad jurídica, pero se desvirtúa la fuerza vinculante de lo acordado.

En fin, las últimas reformas acaecidas a raíz del Real Decreto-ley 20/2012, de 13 de julio, de medidas para garantizar la estabilidad presupuestaria y de fomento de la competitividad, colocan la guinda en la devaluación de la fuerza vinculante

20 En idéntico sentido, literalmente, STS, S. 3. a 22 octubre 1993 (Ar. 7544), 5 mayo 1994 (Ar. 4315), 16 noviembre 1994 (Ar. 555), 16 de junio de 1995 (AL, núm. 1, 1996, pp. 37 y ss.), 30 noviembre 1995 (Ar. 7907), 18 noviembre 1996 (AL, núm. 10, pp. 671 y ss.)

21 Art. 48.1 EBEP-2007: "...En defecto de legislación aplicable los permisos y su duración serán, al menos, los siguientes» ese "al menos» claramente está estableciendo una regulación mínima susceptible de intervención y mejora, es decir, una norma de mínimos parcialmente dispositiva. Nada que ver con la actual versión "Los funcionarios públicos tendrán los siguientes permisos» Otro ejemplo: art. 50 EBEP-2007 sobre vacaciones de los funcionarios públicos: "Los funcionarios públicos tendrán derecho a disfrutar como mínimo..." frente a la actual redacción "Los funcionarios públicos tendrán derecho a disfrutar, durante cada año natural» es decir eliminando la referencia a como mínimo y alterando la naturaleza dispositiva de la regla por una de carácter absolutamente imperativo. 
de los acuerdos alcanzados en la negociación colectiva de los empleados públicos, al optar por la homogeneización de las regulaciones de la negociación laboral y funcionarial, para perjudicar notablemente a la fuerza vinculante del convenio colectivo, hasta hacerla irreconocible, a pesar de que no haya merecido el reproche (y declaración de inconstitucionalidad) del Tribunal Constitucional ${ }^{22}$.

El artículo 32.2 EBEP excepciona abiertamente la fuerza vinculante de los convenios colectivos al señalar que

Se garantiza el cumplimiento de los convenios colectivos y acuerdos que afecten al personal laboral, salvo cuando excepcionalmente y por causa grave de interés público derivada de una alteración sustancial de las circunstancias económicas, los órganos de gobierno de las Administraciones públicas suspendan o modifiquen el cumplimento de convenios colectivos o acuerdos ya firmados en la medida estrictamente necesaria para salvaguardar el interés público.

A todo ello hay que añadir, que las sucesivas leyes de presupuestos han introducido un trámite de informe previo como requisito imprescindible para la validez de los convenios colectivos del personal laboral al servicio de las Administraciones públicas ${ }^{23}$, que recuerda mucho a la exigencia de aprobación expresa y formal de los Acuerdos de funcionarios públicos, sobre la cual basaba la sala de lo contencioso-administrativo del TS la calificación de supremacía de la Administración en la negociación.

\subsection{El ámbito supramunicipal y autonómico}

Mauri (2008: 402) considera que el artículo 34.2 EBEP, que regula la legitimación negocial de las asociaciones de municipios, al indicar que «una Administración o Entidad pública podrá adherirse a los acuerdos alcanzados dentro del territorio de cada Comunidad Autónoma» establece "un límite de correspondencia territorial fuera del cual no se produciria la legitimación para adherin.

La práctica habitual en la negociación desarrollada en las entidades locales vascas (el UDALHITZ) parte, en efecto, de un ámbito territorial autonómico, es decir, pretende englobar al conjunto de las entidades locales radicadas en la Comunidad Autónoma vasca.

\subsection{La preceptividad de la constitución de las mesas de negociación}

La configuración legal de la negociación colectiva de los funcionarios públicos, unida a otros principios de la organización del Estado y del reconocimiento

22 Vid. Marín (2013).

23 Por todas, el artículo 33 de la Ley 48/2015, de 29 de octubre, de Presupuestos Generales del Estado para el año 2016. 
de la autonomía política, de rango igualmente constitucional, condicionan la libertad de elección de la unidad de negociación y obligan a mirar con especial cuidado a los asuntos relacionados con la estructura de la negociación colectiva en las administraciones públicas.

En este sentido Roqueta (2008: 4-5) entiende que la ley «no deja a la libre decisión de las partes negociadoras el establecimiento de la Mesa general común al personal funcionario y laborali. Ciertamente, el artículo 36.3 EBEP se refiere en términos imperativos ("se constituirá») a la constitución de estas mesas "en la Administración General del Estado, en cada una de las Comunidades Autónomas... y entidades locales»; además, utiliza esa misma imperatividad para la constitución de las mesas a los efectos de la negociación colectiva de los funcionarios públicos (art. 34 EBEP), y todo ello lo hace sin perjuicio de reconocer legitimación negocial a las asociaciones de municipios para la negociación de acuerdos de ámbito supramunicipal o sectoriales, amén de autorizar a los pactos y acuerdos (art. 38.7 EBEP) en sus respectivos ámbitos y en relación con las competencias de cada Administración pública, "para establecer la estructura de la negociación colectiva asi como fijar las reglas que han de resolver los conflictos de concurrencia entre las negociaciones de distinto ámbito y los criterios de primacía y complementariedad entre las diferentes unidades negociadoras.»

A la vista de todo este conjunto normativo y de una lectura sistemática del mismo cabe deducir que corresponde, si así lo decide, a la negociación colectiva para la determinación conjunta de las materias y condiciones de trabajo del personal funcionarial y laboral al servicio de las correspondientes Administraciones públicas la adopción de reglas sobre estructura de la negociación colectiva. Creo posible que se opte por establecer la primacía de sus acuerdos, frente a los que se establezcan en otros ámbitos, que podemos denominar inferiores, en tanto se trate de la regulación específica de condiciones de trabajo de uno u otro colectivo (funcionarial o laboral), al ser por definición un ámbito (personal) más restringido.

Desde luego, el artículo 200.1 APLEP regula en términos imperativos la constitución de mesas de negociación en cada una de las entidades locales para la negociación de las materias y condiciones de trabajo comunes al personal funcionarial y laboral ${ }^{24}$, y omite las referencias a la constitución (preceptiva) de mesas de negociación específicamente dirigidas a la negociación colectiva de los funcionarios públicos. Parece así que en el anteproyecto vasco de ley de empleo público queda en manos de las mesas para la negociación conjunta la decisión acerca de la oportunidad o no de la constitución de otros órganos negociadores

24 Art. 200.1: "A los efectos de la negociación colectiva del personal empleado público vasco se constituirá una Mesa General de Negociación en el ámbito de la Administración de la Comunidad Autónoma de Euskadi, asi como en cada una de las Administraciones Forales y Entidades Locales y en la Universidad del Pais Vasco". 
para colectivos con necesidades especiales de regulación, como pueden ser bien el personal funcionarial o laboral, o bien regulaciones específicas para sectores concretos (la sanidad, la educación, la justicia, la policía, etc.). Respecto de estos sectores, suele ser, asimismo, habitual la dualidad de regímenes funcionarial, estatutario y laboral, por lo que no hay que descartar que las denominadas mesas sectoriales, asuman, asimismo, la determinación conjunta de materias y condiciones de trabajo para personal funcionario, estatutario y laboral ${ }^{25}$.

En fin, las diferencias entre las denominadas mesas generales y las mesas sectoriales, así como el reconocimiento de la negociación supramunicipal, unido a la previsión explícita de que la estructura de la negociación colectiva puede ser objeto de regulación mediante acuerdos y pactos, así como la atribución a los acuerdos que contengan materias comunes al personal funcionario y laboral de la consideración y efectos previstos en el artículo 83 del Estatuto de los Trabajadores para el personal laboral, ofrece pistas para la posible calificación de estos productos no tanto como convenios colectivos sectoriales cuanto como acuerdos interprofesionales ${ }^{26}$.

\subsection{La constitución de mesas sectoriales en las entidades locales}

El EBEP resuelve adecuadamente otro aspecto que se había señalado como problemático en relación con la eventual necesidad de constitución de mesas sectoriales (para colectivos concretos) en las Entidades Locales al abrir la regulación y dejar en el artículo 34.4 EBEP la puerta abierta a que todas las denominadas Mesas Generales de Negociación (a constituir, también, en cada Entidad Local) puedan tomar la decisión de constitución de Mesas Sectoriales.

Esta previsión se incluye en un apartado que parece destinado a la regulación específica de la negociación colectiva funcionarial, pero que entiendo extensible a la labor de las mesas para la negociación de las materias comunes a personal funcionario y laboral por las razones que vengo de exponer.

\section{Las mesas de negociación en tanto comisiones negociadoras}

La Mesa de Negociación en tanto comisión negociadora es un órgano paritario de composición pluripersonal en el que están representados tanto los in-

\footnotetext{
25 Art. 200.3: "Dependiendo de las Mesas Generales de Negociación y por acuerdo de las mismas podrán constituirse Mesas Sectoriales, en atención a las condiciones específicas de trabajo de las organizaciones administrativas afectadas o a las peculiaridades de sectores concretos de personal empleado público y a su número".

26 La diferencia no es baladí ya que el artículo 84.2 ET impone la prioridad aplicativa del convenio de empresa "respecto del convenio sectorial estatal, autonómico o de ámbito inferior» en una serie de materias, dejando al margen, por lo tanto, de esa prioridad aplicativa a los contenidos de los acuerdos interprofesionales.
} 
tereses de los empleados públicos como los intereses de la Administración ${ }^{27}$. En tanto órgano negociador, aunque su finalidad es alcanzar un acuerdo, cada representación es portadora de un interés distinto y enfrentado al de la otra parte en la negociación ${ }^{28}$, encontrándose ambos intereses en pie de igualdad (paridad), de ahí el carácter bipartito y paritario de la Mesa. En este aspecto sí se respeta la igualdad entre las partes, aunque a la hora de regular la eficacia de los acuerdos alcanzados la misma se pierda. La paridad puede entenderse de muchas maneras $y$, en función de ello, tener un reflejo en la composición de la Mesa, haciendo hincapié en la necesidad de que cada parte esté representada por el mismo número de representantes o, dar un paso más, para que la paridad se refleje en las reglas de funcionamiento y, concretamente, en la adopción de acuerdos, de tal forma que la adopción de decisiones por parte del órgano pluripersonal y colegiado en que consiste la Mesa de Negociación, se articule a través de un proceso complejo en el que primeramente se conformaría la voluntad de cada una de las representaciones, para, a continuación, pasar a considerar que ambas están conformes o disconformes con una determinada cuestión. El EBEP avanza considerablemente en una concepción cualitativa de la paridad, como trataré de explicar a continuación.

Por lo demás, como recuerda la STC 80/2000, de 27 de marzo, hay que tener en cuenta lo heterogéneo de la representación sindical de los empleados públicos. La representación de los empleados se atribuye a diferentes organizaciones sindicales, las cuales no suelen compartir una misma estrategia en la defensa de los intereses de sus representados, siendo imprescindible para la garantía efectiva de la libertad sindical de cada uno de los sindicatos implicados no tanto que la Administración abra procesos de diálogo con cada una de ellas, sino que les dé la oportunidad de debatir de forma conjunta, de cara a que cada organización contraste sus pareceres y desarrolle su estrategia en confrontación o en contraste con las restantes ${ }^{29}$. Por otro lado, ya se han mencionado algunos de los proble-

27 Roqueta (1996, 183).

28 La contraposición de intereses que marca la diferencia entre las dos representaciones presentes en las comisiones negociadoras suele expresarse así, por ejemplo el art. 2 del Convenio núm. 154 OIT indica que "A los efectos del presente Convenio, la expresión [negociación colectiva] comprende todas las negociaciones que tienen lugar entre un empleador, un grupo de empleadores o una organización o varias organizaciones de empleadores, por una parte, y una organización o varias organizaciones de trabajadores, por otra,...» El art. 33.1 párrafo segundo del EBEP, en esa línea, indica que "... se constituirán Mesas de negociación, en las que estarán legitimados para estar presentes, por una parte, los representantes de la Administración pública correspondiente y, por otra, las organizaciones sindicales...».

29 F.J. 7.o STC 80/2000: «...debe significarse que la negociación colectiva es algo más que el acuerdo final a que, en su caso, aquélla pueda conducir, consistiendo antes que en éste, en la propia actuación negociadora y en las deliberaciones por medio de las que se va realizando. A ello debe añadirse el dato de la configuración colegial de la Mesa de Negociación y de la negociación misma a ella confiada, que difiere muy sensiblemente de un hipotético modo de negociación en el que cada uno de los integrantes de la mesa negociase al margen del colegio. La pluralidad de los miembros del colegio, portadores de intereses distintos, y el conocimiento por cada uno de ellos de las posiciones de los demás en la negociación, con el consiguiente 
mas y de las soluciones aportadas por el EBEP en cuanto a la representación de la Administración, en especial en el ámbito supramunicipal o en el caso de que el ámbito de la negociación abarque a varias administraciones territoriales. A ello se añade ya dentro de cada una de ellas, el hecho de que la representación administrativa suele recaer sobre diferentes altos cargos que ostentan diferentes carteras y que suelen presentar formas diferentes de ver las cosas en relación con las cuestiones debatidas en la negociación colectiva, siendo determinante la función de los órganos colegiados de gobierno para la fijación de una línea de actuación uniforme y coordinada ${ }^{30}$.

Coherentemente con su diferente naturaleza, cada una de las representaciones presenta unas reglas de legitimación distintas, por lo que es necesario diferenciar las normas relativas a la representación de la Administración en la Mesa de Negociación, de las que afectan a la representación de los empleados.

\subsection{La problemática de la representación de la Administración pública en la negociación colectiva conjunta de personal laboral y funcionarial para las Entidades Locales y Forales radicadas en una Comunidad Autónoma}

El artículo 34.2 $\mathrm{EBEP}^{31}$ señala

Se reconoce la legitimación negocial de las asociaciones de municipios, así como la de las Entidades Locales de ámbito supramunicipal. A tales efectos, los municipios podrán adherirse con carácter previo o de manera sucesiva a la negociación colectiva que se lleve a cabo en el ámbito correspondiente.

Asimismo, una Administración o Entidad Pública podrá adherirse a los acuerdos alcanzados dentro del territorio de cada Comunidad Autónoma, o a los acuerdos alcanzados en un ámbito supramunicipal.

El APLEP, en la misma línea, recoge un artículo 202 sobre «Negociación colectiva por asociaciones municipales y entidades supramunicipales»:

\footnotetext{
interés de poder debatir la posición de cada uno de ellos, pone de manifiesto que no son equiparables la negociación en el seno del colegio, y las negociaciones separadas. Resulta claro, por tanto, que el derecho a negociar en un determinado colegio no se satisface mediante la negociación alternativa del Sindicato con la Administración al margen de éli. El TC no niega el carácter bipartito ni el contraste de intereses entre los propios de la Administración y el de los funcionarios públicos o sus representantes sindicales, sino que pretende poner de manifiesto lo heterogéneo de la representación sindical de los funcionarios públicos, es decir, del banco sindical compuesto habitualmente por un número de representantes de diferentes organizaciones sindicales las cuales no suelen compartir una misma estrategia en la defensa de los intereses de sus representados.

30 Del Rey (1989, 45 y 46) señala como característica peculiar de la negociación colectiva que afecta a los funcionarios públicos la conflictividad ínter orgánica entre los diferentes órganos competentes en la determinación de sus condiciones de trabajo.

31 Por todos, ver un comentario de este precepto en Mauri (2008, 401-404).
} 
1. Se reconoce la legitimación negocial de las asociaciones de municipios y, en concreto la de Euskadiko Udalen Elkartea-Asociación de Municipios Vascos (EUDEL) o, en su caso, la que resulte ser la más representativa de los municipios vascos, para acordar con las organizaciones sindicales más representativas en el ámbito local las condiciones de trabajo del personal empleado público de las entidades locales vascas. También se reconoce la legitimación negocial a las Entidades Locales de ámbito supramunicipal.

A tales efectos, los municipios podrán adherirse con carácter previo o de manera sucesiva a la negociación colectiva que se lleve a cabo en el ámbito correspondiente. Asimismo, una administración o entidad pública podrá adherirse a los acuerdos alcanzados dentro del territorio de cada Comunidad Autónoma, de cada Territorio Histórico o a los acuerdos alcanzados en un ámbito supramunicipal.

Tanto el EBEP como el APLEP están poniendo en valor lo que era una práctica habitual, al menos, pero no sólo, en las administraciones públicas vascas. En la misma línea, la Federación española de Municipios y Provincias formará parte de la mesa para la negociación de las materias susceptibles de regulación estatal con carácter de norma básica (art. 36. 1 y 2 EBEP).

El DGVORAP, en su artículo 17.2, que ya he mencionado antes, reconoce la posibilidad de negociación colectiva conjunta y para diferentes Administraciones públicas vascas, pero no desarrolla el marco jurídico al que puede someterse esa negociación ya que no concreta cuáles sean los órganos competentes de las Administraciones Públicas Vascas para proceder a esa negociación. En la práctica, ha sido EUDEL la entidad que se ha encargado de representar a las Entidades Locales vascas en la negociación colectiva para la determinación conjunta de las condiciones de trabajo de funcionarios y personal laboral al servicio de las Entidades Locales (y con el ARCEPAFE, Forales).

Me parece un gran avance que el EBEP asuma la existencia de una realidad necesitada de tutela legal para aquellas prácticas consistentes en la regulación de condiciones de trabajo homogéneas para los empleados públicos al servicio de diferentes Administraciones públicas territoriales y sus organismos autónomos, o dicho de otra forma, para el conjunto de Entidades Locales radicadas en el ámbito de una comunidad autónoma, que sería el supuesto concreto del UDALHITZ y el que, como he tenido ocasión de indicar más arriba, está regulando el art. 34.2 EBEP.

En primer lugar, la negociación supramunicipal es compatible con la constitución (preceptiva) de Mesas de Negociación en cada una de las Entidades Locales para la negociación colectiva de los funcionarios públicos (en cuyo caso la mesa tendrá una composición) o para la negociación de las materias comunes al personal funcionario y laboral de cada Administración (en cuyo caso su composición será otra). Aunque la filosofía de acuerdos como el UDALHITZ sea la de ofrecer una regulación completa de determinadas materias, sustituyendo, 
por decirlo de alguna manera, la negociación a desarrollar en el ámbito local, lo cierto es que el EBEP ofrece total libertad al ámbito territorial y funcional inferior, esto es, al ámbito local, para adherirse o no a lo acordado en el ámbito supramunicipal.

En segundo lugar, hay que tener en cuenta que las antes citadas mesas que en teoría hay que constituir en cada Entidad Local,

quedarán válidamente constituidas cuando, además de la representación de la Administración correspondiente, las organizaciones sindicales que las conforman representen, como mínimo, la mayoría absoluta de los miembros de los órganos unitarios de representación en el ámbito de que se trate (art. 35.1).

Pueden existir entidades locales de muy pequeña dimensión que tengan problemas para la constitución de comisiones negociadoras válidas o para que exista una negociación colectiva real, de donde la idea de una negociación supramunicipal para la cobertura de vacíos resulta una solución adecuada.

En tercer lugar, cabe preguntarse hasta qué punto son exigibles a la negociación colectiva en las Administraciones públicas los requisitos sobre legitimación empresarial para la negociación en el ámbito superior a la empresa. Recientemente, se está viviendo en especial en el territorio de Gipuzkoa una conflictividad candente en torno a la exigencia legal de que las asociaciones empresariales cuenten con el diez por ciento de los empresarios, siempre que den ocupación al diez por ciento de los trabajadores afectados, así como que den ocupación al quince por ciento de los trabajadores afectados, a lo que hay que añadir que para la válida constitución de la comisión negociadora se exige que representen como mínimo, a empresarios que ocupen a la mayoría de los trabajadores afectados por el convenio, todo ello en el ámbito de la negociación colectiva sectorial y provincial. En realidad estas reglas de legitimación se aplican a la negociación colectiva sectorial y no a la negociación colectiva interprofesional, la cual reconduce al concepto de asociaciones empresariales más representativas de carácter estatal o de comunidad autónoma. El EBEP no entra en ese detalle y se limita a reconocer la legitimación negocial de las asociaciones de municipios con independencia de su implantación. El APLEP, sin embargo, sí introduce el concepto de la asociación que resulte ser la más representativa, si bien no procede a desarrollar ese concepto indeterminado. La acreditación de los entes locales asociados y trabajadores o funcionarios a los que dan ocupación no debería resultar problemático en este ámbito, lo que resulta más dudoso es que las exigencias de la norma laboral se extiendan a este supuesto.

El hecho de que la negociación supramunicipal requiera de la adhesión de cada Entidad Local, sumado a que no se barajan mecanismos tácitos de adhesión, resta importancia a la discusión sobre la representatividad de las asociaciones de municipios. Ahora bien, no está de más que se anticipen y, por lo tanto, 
se traten de resolver los problemas derivados del hecho de que exista más de una asociación de municipios interesada en intervenir en la negociación colectiva.

En cualquier caso a la vista está que los órganos de gobierno de las respectivas administraciones públicas tienen importantes funciones respecto de la negociación colectiva desarrollada en los ámbitos que les afectan ya que, en definitiva, les corresponde corroborar o aprobar lo acordado. Las competencias de esos órganos de gobierno sobre la organización administrativa da lugar a que en ocasiones Administración y Gobierno se confundan, surgiendo la duda sobre quién sea realmente la contraparte en la negociación colectiva con los empleados públicos $^{32}$. La contraparte es la Administración pública, correspondiendo a las normas que regulan la organización administrativa decidir quién ostenta en cada caso la representación de esas personas jurídicas complejísimas. En ocasiones, dicha representación recaerá sobre sus órganos de dirección por excelencia, los cuales, en tanto órganos colegiados, suelen actuar mediante representantes.

En esa línea, el art. 33.2 EBEP prevé que

Las Administraciones públicas podrán encargar el desarrollo de las actividades de negociación colectiva a órganos creados por ellas, de naturaleza estrictamente técnica, que ostentarán su representación en la negociación colectiva previas las instrucciones políticas correspondientes y sin perjuicio de la ratificación de los acuerdos alcanzados por los órganos de gobierno o administrativos con competencia para ello.

\subsection{La representación de los empleados públicos en la Mesa de Negociación para la negociación conjunta}

\subsubsection{Delimitación conceptual: la capacidad y la legitimación negociadora}

En el ámbito laboral es habitual distinguir entre la capacidad y la legitimación para negociar ${ }^{33}$. La capacidad definiría la aptitud genérica para la negociación colectiva. La legitimación sería la aptitud específica para negociar en un determinado ámbito ${ }^{34}$.

La capacidad representativa del sindicato para negociar depende de la afiliación, es decir, todo sindicato está legitimado para representar los intereses de sus

32 Mauri (1995: 259) considera al Consejo de Ministros, a los Consejos de Gobierno de las Comunidades Autónomas y a los órganos correspondientes de las Entidades Locales, como «un órgano externo a los sujetos legitimados para negociar y al propio procedimiento convencional,...".

33 En el ámbito de la negociación colectiva de los funcionarios públicos, por todos, ver Roqueta (1996: 186 y ss.).

34 Alonso y Casas (2002, 831»: «...la negociación de un convenio colectivo se desarrolla entre representantes de trabajadores y empresarios con capacidad o aptitud genérica para convenir, y legitimación o aptitud especifica para celebrar un convenio colectivo determinado. Si el ordenamiento parte de la base de que los legitimados pueden y deben asumir la representación negocial de trabajadores y empresarios en principio no representados por ellos, precisan entonces los legitimados de una legitimación ampliada». 
afiliados en la negociación colectiva con su empleadora (art. 28.1 CE). Ahora bien, existen diferentes grados de capacidad representativa, partiendo del hecho de que habitualmente el legislador se ve obligado a intervenir sobre esa aptitud genérica de todo sindicato para representar a sus afiliados, en orden a garantizar convenientemente la eficacia personal general del convenio colectivo, así como por la necesidad de limitar el número de componentes de las comisiones negociadoras $^{35}$. Tomando en consideración lo anterior se suele hablar de legitimación inicial como aptitud específica para negociar en un determinado ámbito y designar representantes en la comisión negociadora y de legitimación plena como aptitud específica para formar parte de la comisión negociadora. Las reglas en torno a la legitimación inicial determinan a los sujetos que han de decidir la composición numérica de la comisión y el reparto de puestos entre los inicialmente legitimados. Las reglas sobre legitimación plena se refieren precisamente a dicha composición numérica, así como a la distribución de puestos, acabando por concretar los componentes reales de la comisión. De acuerdo con estos diferentes conceptos, el legislador debe establecer criterios para la selección de aquellas organizaciones sindicales que puedan ser consideradas como los representantes adecuados de todos los empleados públicos incluidos en la unidad de negociación, así como de reglas acerca de composición numérica de las comisiones negociadoras y para la correcta distribución de los puestos de la comisión negociadora entre los inicialmente legitimados.

El EBEP siguiendo la línea de sus antecesoras establece un monopolio sindical cualificado ${ }^{36}$ a la hora de definir a los representantes de los empleados públicos en la negociación colectiva, ya que, por un lado, sólo reconoce legitimación a las organizaciones sindicales y, por otro, no legitima a todo sindicato, sino únicamente a aquéllos que gocen de una especial capacidad representativa.

\subsubsection{La capacidad para negociar}

La aptitud general para negociar corresponde a todos los sindicatos, según el art. 28.1 CE y 2.2, d) LOLS. El art. 1.5 LOLS, no es óbice para reconocer que el derecho a la negociación colectiva forma parte de la libertad sindical reconocida a todo sindicato, lo que les hace titulares de la capacidad para negociar las condiciones de trabajo de sus afiliados. El ET opta, asimismo, por reconocer capacidad negociadora en el ámbito de la empresa a los representantes unitarios, opción rechazada por el EBEP, incluso en ámbitos reducidos como las entidades locales. La opción de establecer un monopolio sindical para la negociación colectiva de los funcionarios no merece reproche constitucional ${ }^{37}$.

35 Vid. Del Rey (1988: 192) y Roqueta (1996: 186 y ss.).

36 En relación con la LORAP, Del Rey (1988: 192) y Roqueta (1996: 196).

37 En opinión de la doctrina mayoritaria la exclusión de la legitimación negocial a la representación unitaria no plantea problemas de constitucionalidad. Vid. Roqueta (1996: 191). 


\subsubsection{La legitimación inicial}

La opción por un sistema de eficacia personal general para los productos de la negociación colectiva obliga a seleccionar entre las organizaciones sindicales capacitadas para la negociación colectiva, a aquellas susceptibles de representar al conjunto de los empleados de dicho ámbito. La ley concede legitimación, entendida como aptitud específica para negociar en un ámbito concreto, a aquellas organizaciones sindicales que demuestren tener una especial capacidad representativa dentro de la unidad de negociación ${ }^{38}$, que les permita actuar no sólo en representación de sus afiliados, sino del conjunto de los empleados, con independencia de su afiliación a un determinado sindicato.

La ley estatal (la LOLS, el ET y el EBEP) se ha tenido que enfrentar al problema de la selección del interlocutor adecuado para llevar a cabo una negociación colectiva de ámbito personal general, y todo ese conjunto normativo hace pivotar la legitimación para la negociación colectiva sobre los órganos de representación unitaria - delegados de personal, Comités de Empresa y Juntas de personal-, obligando al sindicato a servirse de ellos para implantarse en la empresa.

El EBEP, con clara inspiración en las reglas del ET sobre la negociación de ámbito supra empresarial, reconoce legitimación inicial a las organizaciones sindicales más representativas a nivel estatal y de Comunidad Autónoma, así como a las organizaciones sindicales que hayan obtenido el diez por ciento o más de los representantes en las elecciones a los órganos de representación de personal, que en función del ámbito serán los delegados y juntas de personal o éstos y los comités de empresa, en el ámbito de que se trate ${ }^{39}$.

\subsubsection{La legitimación plena}

La LORAP no señalaba nada más en relación con la constitución de las Mesas de Negociación, quizás por considerar que las bases del estatuto de los funcionarios públicos no debían entretenerse en cuestiones de detalle sobre la composición numérica de las mesas, las reglas de distribución de puestos entre los sindicatos inicialmente legitimados o el establecimiento de criterios para considerar la mesa válidamente constituida en atención a la representatividad efecti-

38 Por todas, el F.J. 10. STC 98/1985: «Se trata de un supuesto específico de negociación, dotada de eficacia general y aplicable por tanto a todos los trabajadores y empresarios incluidos dentro de su ámbito, pertenezcan o no a las organizaciones pactantes. Es este carácter, y la necesidad lógica de reconocer la legitimación a quienes representen cualificadamente los intereses del grupo afectado, los que justifican la limitación a quienes ostentan una minima representatividad..."

39 Roqueta (2008: 6) pone de manifiesto un problema de infrarrepresentación de los funcionarios públicos como consecuencia de las diferentes reglas que rigen la constitución de unidades electorales para Juntas y delegados de personal de los funcionarios públicos y Comités de empresa y delegados de personal para el personal laboral al servicio de las Administraciones públicas. 
vamente ostentada por las organizaciones presentes en la misma. Sea como sea, lo cierto es que la LORAP tampoco desarrolló esta cuestión para la negociación en la Administración General del Estado y las normas dictadas por la CAV también hacen caso omiso de estas cuestiones. El resultado es que ante la ausencia de reglas explícitas la sala de lo contencioso-administrativo del Tribunal Supremo optó por una interpretación rígida e inflexible de la LORAP en sus mismos términos, rechazando sistemáticamente las pretensiones de aquellas organizaciones sindicales que deseaban estar presentes en las mesas de negociación en función de la representatividad que ostentaban efectivamente. Como consecuencia, esta interpretación judicial, que negaba cualquier posibilidad de completar las reglas de la LORAP con las del ET, acabó configurando a las Mesas de Negociación como órganos negociadores que poco o nada tenían que ver con las comisiones negociadoras del ET, favoreciendo, por un lado, la desconexión entre representantes sindicales de los funcionarios en la negociación y éstos últimos y, por otro, las dificultades para proceder a una negociación colectiva conjunta de personal laboral y funcionarial debido a las diferentes reglas que regían la composición del órgano negociador en uno y otro caso.

El art. 35.1 EBEP zanja por fin esta cuestión, dejando sin argumentos al TS, para especificar, en los mismos términos que el art. 88.1 párrafo segundo ET, que las Mesas de Negociación

quedarán válidamente constituidas cuando, además de la representación de la Administración correspondiente, y sin perjuicio del derecho de todas las organizaciones sindicales legitimadas a participar en ellas en proporción a su representatividad, tales organizaciones sindicales representen, como mínimo, la mayoría absoluta de los miembros de los órganos unitarios de representación en el ámbito de que se trate.

Este criterio se relaciona con la legitimación plena y garantiza una relación efectiva entre la representación y las personas físicas representadas.

El DGVORAP no determina el número máximo de puestos o de representantes por cada una de las partes (Administración pública y organizaciones sindicales) ni, en su caso, las reglas de reparto del número de puestos disponible. El EBEP subsana esta laguna y establece reglas sobre la composición numérica de las Mesas de Negociación y los criterios que deben regir la distribución de puestos entre los inicialmente legitimados, fijando un régimen idéntico al del ET, lo cual permitirá superar la doctrina judicial de la sala de lo contencioso-administrativa del TS antes citada.

$\mathrm{El}$ art. 35.4 EBEP recogiendo las normas del ET sobre negociación colectiva en el ámbito superior a la empresa, señala que "en las normas de desarrollo del presente Estatuto se establecerá la composición numérica de las Mesas correspondientes a sus ámbitos, sin que ninguna de las partes pueda superar el número de quince miembros». El APLEP reproduce literalmente esta norma, art. 200.5, es decir, 
que no se ha dado como aludido en la referencia a las normas de desarrollo. En todo caso, no es de extrañar que se opte por un régimen abierto en cuanto a la composición numérica de las comisiones negociadoras, que es, asimismo, la opción del artículo 88.4 ET. Este precepto, por un lado, impone a las normas estatales — para la burocracia de la AGE - y autonómicas sobre estatuto de los funcionarios públicos que establezcan la composición numérica de las mesas correspondientes, lo cual obliga a los legisladores a intervenir en esta cuestión. Por otro, establece una regla de salvaguarda señalando el número máximo de puestos por cada parte, y lo fija en quince que, como acabo de decir, es el número establecido en el ET para la composición de las comisiones negociadoras de ámbito superior a la empresa. Lo que se echa en falta es que, a diferencia de lo que ha sucedido con reformas anteriores del marco jurídico regulador de la negociación colectiva funcionarial, no se haya optado por los poderes públicos vascos por reformar el DGVORAP.

El nuevo EBEP no sólo regula composición numérica de la comisión, sino que fija los criterios que han de regir la distribución de los puestos entre los inicialmente legitimados, así como la designación de los componentes de la Mesa.

Por lo que respecta a la distribución de puestos, el art. 35.1 EBEP reconoce el derecho de todas las organizaciones sindicales inicialmente legitimadas a participar en las Mesas de Negociación en proporción a su representatividad, si bien no aclara de qué forma se mide la representatividad de las organizaciones sindicales, si en función del porcentaje de votos obtenido en las elecciones o bien en función del número de representantes electos logrado.

El EBEP añade a lo anterior un requisito para la válida constitución de la comisión negociadora en virtud del cual no es suficiente con garantizar la presencia en la mesa de negociación de todas las organizaciones sindicales inicialmente legitimadas. Según el art. 35.1 EBEP las Mesas de Negociación «quedarán válidamente constituidas cuando [...] tales organizaciones sindicales representen, como minimo, la mayoría absoluta de los miembros de los órganos unitarios de representación en el ámbito de que se trate».

El establecimiento de un número máximo de puestos plantea el problema de su concreción. Sobre este precepto destacaría dos ideas. En primer lugar, que el EBEP establece el número máximo de miembros y que dicho límite resulta indisponible, por lo tanto, se puede decidir que cada parte cuente con un número inferior de representantes, pero no se puede superar dicho número. En defecto de regla expresa al respecto, serán las partes — administración pública y organizaciones sindicales inicialmente legitimadas - quiénes de mutuo acuerdo decidirán la concreta composición de la Mesa. En segundo lugar, la cuestión relativa a la composición numérica de las comisiones negociadoras ha sido objeto de análisis por parte de la jurisprudencia social, en tanto que suele ser fuente de conflictos intersindicales. En efecto, las organizaciones sindicales legitimadas suelen 
enfrentarse entre sí a la hora de decidir la concreta composición de las comisiones negociadoras en determinados ámbitos. En este sentido, la sala de lo social del TS ha señalado que no corresponde a los jueces decidir sobre la adecuación de una determinada composición numérica de la comisión negociadora, a no ser que dicha determinación numérica tenga como finalidad la obtención de una posición mayoritaria injustificada en el seno de la comisión negociadora ${ }^{40}$.

\section{Las materias objeto de negociación en las Mesas}

Para analizar esta cuestión voy a partir de los artículos 36.1; 36.3 y 37 y concordantes del EBEP, así como del DGVORAP, el anteproyecto de ley de empleo público vasca y del contenido de los UDALHITZ.

El art. 36.1 EBEP deja claro que el incremento global de las retribuciones del personal al servicio de las Administraciones públicas que corresponda incluir en el proyecto de ley de Presupuestos Generales del Estado de cada ańo constituye una materia "común» al personal funcionario, estatutario y laboral que debe ser negociada en el seno de lo que se puede llamar como súper mesa general «conjunta» de negociación (art. 36.1. EBEP: Mesa General de Negociación de las Administraciones públicas). En la medida en que se establezca como norma absolutamente imperativa quedaría al margen de la posible negociación en ámbitos territoriales y funcionales inferiores.

En todo caso, las materias comunes no se agotan en el incremento global de las retribuciones y así lo entiende el propio EBEP al señalar en su artículo 36.3 EBEP que "Para la negociación de todas aquellas materias y condiciones de trabajo comunes al personal funcionario, estatutario y laboral de cada Administración pública, se constituirá..."; ahora bien, como se puede apreciar, el EBEP no concreta cuáles sean esas otras materias comunes ni en el artículo 36.3 EBEP ni en el artículo 37 EBEP relativo a las materias objeto de negociación, ni en el artículo 38 sobre Pactos y Acuerdos y en el que se incluyen importantes precisiones sobre el contenido de los Pactos y Acuerdos y, por ende, de la negociación colectiva de los empleados públicos.

\subsection{Las materias objeto de negociación}

Teniendo en cuenta que este artículo trata de realizar propuestas para el desarrollo efectivo de la negociación colectiva "conjunta» y «supra local» para el conjunto de las Entidades (Forales y) Locales de una Comunidad Autónoma (la vasca) no me voy a entretener en el comentario de los problemas derivados de la

$40 \mathrm{Al}$ respecto ver la STC 137/1991. 
negociación de las bases del estatuto de los empleados públicos, para centrarme en los problemas interpretativos, si es que los hay, del artículo 36.3 EBEP y concordantes.

Como vengo diciendo, personalmente considero que existen dificultades para determinar el concepto jurídico indeterminado que emplea el artículo 36.3 EBEP al referirse a las materias «comunes».

El desarrollo de las bases, a través del DGVORAP (que recordemos es muy anterior en el tiempo al EBEP) no especifica mucho más. Por un lado, en la misma línea que el EBEP menciona expresamente las retribuciones, que se constituyen así en la materia común por antonomasia, pero el DGVORAP deja el elenco abierto al referirse a la posibilidad de la determinación conjunta de las retribuciones y condiciones de trabajo de los empleados públicos ${ }^{41}$. El hecho de que hable de posibilidad y no de deber, a diferencia del EBEP, y de determinación conjunta de condiciones de trabajo, que pueden ser comunes o no, le da un carácter mucho más abierto al elenco de eventuales materias a incluir en esos acuerdos «conjuntos». Es decir, el DGVORAP va en la línea de promover, a través de la negociación colectiva la homogeneización de las condiciones de trabajo de los empleados públicos, dando a entender que la lista de condiciones de trabajo «comunes» dependerá de la voluntad de los negociadores.

La doctrina científica, a la hora de analizar el EBEP y las dificultades de concreción de sus mandatos, se ha dividido entre quien considera, asimismo, que corresponde a la propia negociación colectiva la determinación de cuáles sean las materias comunes a negociar ${ }^{42}$ y quien entiende que no cabe hurtar a las respectivas «mesas de negociación funcionariales» $\mathrm{y}$ "comisiones negociadoras laborales» sus materias propias, por lo que trata de identificar mediante una lista más o menos cerrada, las materias y condiciones de trabajo comunes (Roqueta, 2008: $8^{43}$ ).

En todo caso, además del artículo 37 EBEP, habría que tener en cuenta lo previsto en la disposición adicional séptima del EBEP sobre planes de igualdad, en cuyo punto segundo se señala que «...las Administraciones públicas de-

${ }^{41}$ Recordemos que el artículo 18.2 DGVORAP, en la redacción dada por el Decreto del Gobierno Vasco 228/1990, de 4 de septiembre, señala literalmente lo siguiente: "A tal fin, el Gobierno Vasco y/o los órganos de gobierno de las Administraciones Forales y Locales de la Comunidad Autónoma del País Vasco podrán alcanzar acuerdos para la determinación conjunta de las retribuciones y condiciones de trabajo de los empleados públicos al servicio de diferentes Administraciones Públicas Vascas».

42 Según ROQUETA, 2008, 8 se incluiría en esta línea, López (2008: 247).

43 Roqueta precisa como materias comunes las siguientes: los criterios generales en materia de planes e instrumentos de planificación de recursos humanos, sistemas de clasificación de puestos de trabajo, ofertas de empleo público, acceso y evaluación del desempeño; el incremento de las retribuciones del personal al servicio de la correspondiente Administración; la formación continua; la salud laboral; los planes de Previsión Social Complementaria. Estas materias, que constituyen el núcleo duro del régimen estatutario del empleado público, están reguladas en el EBEP por normas comunes al personal funcionario y laboral y, por lo tanto, permeables a la relación de empleo público». 
berán elaborar y aplicar un plan de igualdad a desarrollar en el convenio colectivo o acuerdo de condiciones de trabajo del personal funcionario que sea aplicable, en los términos previstos en el mismo.» Un plan de igualdad en una Administración pública que no contemple conjuntamente la situación de mujeres y hombres, funcionarias, estatutarias y trabajadoras por cuenta ajena será un plan de igualdad incompleto y es que se ha de ser especialmente vigilante con el hecho de que las diferencias entre los regímenes jurídicos funcionarial y laboral (en cuanto a retribuciones, sistemas de clasificación profesional, estabilidad en el empleo, consideración como empleados a tiempo parcial o completo, condiciones para el acceso y promoción, por mencionar algunas) no repercutan en discriminaciones más o menos encubiertas, por ello entiendo que los planes de igualdad son materia adecuada para su determinación conjunta, sin perjuicio de que deban contemplar las especificidades propias de personal funcionario y laboral. Todo ello sin perjuicio del carácter transversal del derecho a la igualdad de trato y oportunidades en el ámbito laboral que impregna, por lo tanto, todas y cada de las materias y condiciones de trabajo de las personas empleadas públicas en sus respectivos estatutos así como otras materias que deben o pueden ser incluidas en la negociación colectiva.

\subsection{El contenido de los Pactos y Acuerdos}

El artículo 38 sobre Pactos y Acuerdos, por una parte, incluye referencias a su contenido "necesario" (art. 38.4 y 5 EBEP) y, por otro, a su contenido "posible» (art. 38.9 EBEP). Este contenido posible de los Pactos y Acuerdos, que hace referencia a la estructura de la negociación colectiva resulta especialmente importante por lo que a la negociación colectiva conjunta supralocal se refiere, sobre todo si tenemos en cuenta que el artículo 38.8 EBEP equipara la naturaleza y efectos de estos acuerdos con los del artículo $83 \mathrm{ET}$, para el personal laboral, consideración totalmente coherente con el hecho de que sean negociados por asociaciones «empresariales» y organizaciones sindicales especialmente representativas y su ámbito superior a la empresa.

En cuanto a los contenidos del UDALHITZ ${ }^{44}$, se echa de menos en su publicación como anuncio, los considerandos y acuerdos que conforman el protocolo constituyente del marco sectorial de relaciones laborales para las instituciones locales de Euskadi, de 28 de abril de 2008, suscrito, de una parte, por EUDEL, en representación de los Ayuntamientos de la Comunidad Autónoma Vasca y, de la otra, por ELA, CC.OO. y UGT.

${ }_{44}$ El Acuerdo regulador de las condiciones de trabajo del personal de las instituciones locales vascas UDALHITZ 2008-2010, que salvo error u omisión, es el último suscrito, se puede consultar en el BOPV, n. ${ }^{\circ} 231$, de dos de diciembre de 2008. No obstante, en la página web de EUDEL se puede consultar una versión más extendida de este acuerdo (http://www.eudel.eus/es/documentos/ otros/ficheros/UDALHITZ_2008_2010_anexo_ii nuevo_texto_refundido_) 
Este protocolo completa los contenidos del acuerdo, con referencias explícitas (e indispensables) a las partes que lo conciertan, a su ámbito personal, funcional y territorial; así como con referencias explícitas a la estructura de la negociación colectiva, al mencionar a "los temas reservados susceptibles de negociación en las mesas de cada Institución» (acuerdo cuarto) y fijando las reglas que han de resolver los conflictos de concurrencia entre las negociaciones de distinto ámbito, de manera muy respetuosa y escrupulosa con las interpretaciones más literales y restrictivas sobre el ámbito de actuación de estos acuerdos supra locales al recordar, por un lado, que los Ayuntamientos y demás entidades locales de la Comunidad Autónoma Vasca deben adherirse al acuerdo.

Por otro lado, las partes signatarias acuerdan que, para facilitar al máximo la integración de las entidades locales en el acuerdo, en aquellas instituciones en las que existan acuerdos vigentes con la representación sindical éstos seguirán en vigor, sin perjuicio de la posibilidad de que se adhieran a los presentes acuerdos por decisión de las partes signatarias de aquellos.

Por último, invitan a todas las instituciones locales concernidas por este protocolo y a las representaciones sindicales en las mismas a abstenerse de iniciar procesos de negociación sobre las materias objeto de esta Mesa y así evitar duplicidades negociadoras de compleja gestión posterior.

En cuanto a las materias y condiciones de trabajo que el UDALHITZ considera que deben ser objeto de determinación conjunta, a la vista de sus contenidos, son las siguientes: Un Título Preliminar, con los contenidos mínimos, completado con el establecimiento de sistemas o procedimientos para el conocimiento y resolución de los conflictos derivados de la aplicación e interpretación del acuerdo: la inclusión de esta materia en Pactos y Acuerdos en el EBEP y a diferencia del ET es voluntaria. Una de las cuestiones que suscita la creación, configuración y desarrollo de sistemas de solución extrajudicial de conflictos colectivos y la opción del UDALHITZ de entretenerse en su regulación se refiere a su articulación con el acuerdo interprofesional Preco que se concibe como de aplicación al personal laboral al servicio de las Administraciones públicas. Esta cuestión, no obstante, habrá que dejarla para mejor ocasión.

El Título Primero, se dedica al tiempo de trabajo, regulando la jornada de trabajo, descansos y fiestas, vacaciones, servicios extraordinarios, licencias y permisos. En el protocolo, se menciona como tema reservado susceptible de negociación en las mesas de cada Institución, las horas extraordinarias. El Título Segundo regula el régimen de retribuciones y se considera tema reservado susceptible de negociación en las mesas de cada Institución, las actualizaciones retributivas de carácter no general. El Título Tercero, el sistema de protector complementario de prestaciones pasivas (ELKARKIDETZA) y otras mejoras 
asistenciales. El Título Cuarto se refiere a la selección de personal, provisión de puestos de trabajo y fomento de la promoción interna. Título Quinto la prevención de riesgos laborales y planes de igualdad; se consideran temas reservados susceptibles de negociación en las mesas de cada Institución, las medidas contra el acoso laboral y violencia de género. Título Sexto: la acción sindical. Título Séptimo medidas de impulso del estudio del euskera (o «derechos lingüísticos» como materia desgajada de la formación). Título Octavo: a la estabilidad laboral y calidad en el empleo, ofertas de empleo público y subrogación.

En fin, por lo que respecta al Anteproyecto de ley vasca de empleo público, la misma proclama su compromiso con la equiparación de condiciones de trabajo entre personal funcionario y laboral al servicio de las Administraciones públicas vascas y, coherentemente con dicho compromiso, por un lado, equipara los principios generales para la ordenación de la negociación colectiva tanto para personal funcionario como laboral (los principios son únicos) y, por otro, fija la obligación de constitución de Mesas de Negociación a los efectos de la negociación colectiva del personal empleado público vasco, competentes para la negociación de las materias y condiciones de trabajo comunes al personal funcionario, estatutario y laboral de su ámbito, pudiendo constituirse, dependiendo de dichas Mesas Generales de Negociación y por decisión de las mismas, Mesas Sectoriales, para la negociación, en su caso, diferenciada de materias y acuerdos para personal funcionario y laboral.

\title{
6. Los acuerdos para la determinación conjunta de condiciones de trabajo de personal funcionario y laboral en el ámbito supralocal: naturaleza y eficacia jurídicas
}

\author{
Según el artículo 38.8 EBEP,
}

Los Pactos y Acuerdos que, de conformidad con el artículo 37, contengan materias y condiciones generales de trabajo comunes a al personal funcionario y laboral, tendrán la consideración y efectos previstos en este artículo para los funcionarios y en el artículo 83 del Estatuto de los Trabajadores para el personal laboral.

Por lo tanto, de acuerdo con Roqueta (2008: 9) en que ostentan una naturaleza dual y que es innecesario que se formalicen en instrumentos negociales separados. El UDALHITZ, sin embargo, se mantiene fiel a la recomendación mayoritaria de la doctrina científica anterior a la promulgación del EBEP y que como manera de salvar las reticencias de la jurisprudencia contra la negociación colectiva conjunta proponía la formalización en dos acuerdos diferentes de lo relativo a los funcionarios y al personal laboral. 
La equiparación a la que procede este artículo 38.8 entre estos acuerdos y los acuerdos interprofesionales del artículo 83 ET no es baladí de cara al establecimiento de reglas de articulación entre los convenios colectivos para el personal laboral al servicio de las Administraciones públicas.

En todo caso lo que marca la diferencia de los acuerdos negociados en el ámbito supramunicipal es la exigencia de adhesión que acompaña a su regulación en el artículo 34.2 EBEP. Aunque no lo indica abiertamente, se reconoce la legitimación negocial de las asociaciones de municipios y, por lo tanto, se permite la negociación que abarca al conjunto de Entidades Locales ubicadas en el territorio de una concreta comunidad autónoma, pero la eficacia de ese producto se hace depender de la previa o posterior adhesión de las entidades afectadas.

Con carácter general, la negociación colectiva de los empleados públicos está sujeta a un procedimiento complejo en donde no queda más remedio que diferenciar el procedimiento negociador propiamente dicho, de la fase de aprobación expresa y formal. Esta fase, a la vista de los preceptos incluidos en las leyes de presupuestos generales que exigen informes preceptivos para la suscripción de convenios colectivos que afecten al personal laboral al servicio de las administraciones públicas, se ha extendido también a la negociación colectiva laboral y es consecuencia de los principios de legalidad, cobertura presupuestaria y competencia que rigen tanto la negociación colectiva funcionarial como la del personal con contrato de trabajo al servicio de las Administraciones públicas, en especial a raíz de la implementación de trascendentales medidas de contención del déficit público. Considero inescindible de la exigencia de la aprobación expresa y formal como requisito subsiguiente al acuerdo, la necesidad de adhesión a los acuerdos supramunicipales.

El respeto al derecho de la negociación colectiva y la consideración sobre la preceptividad de la constitución de mesas generales de negociación en cada entidad local, conduce a defender que la adhesión se debe enmarcar en el proceso negociador a desarrollar en el ámbito de cada Entidad Local concernida, pero no estoy de acuerdo con la consideración de que la interpretación sobre la regulación del EBEP en torno a la adhesión a los acuerdos supramunicipales deba nutrirse de su equiparación con instituciones propias de la negociación colectiva laboral en sentido estricto como la adhesión y extensión de convenios colectivos ${ }^{45}$.

En mi opinión, la adhesión a un acuerdo supramunicipal puede ser una decisión unilateral de los órganos administrativos y de gobierno competentes y una respuesta al fracaso de la negociación en el ámbito correspondiente o a la imposibilidad de desarrollar una negociación colectiva en condiciones.

45 En este sentido, vid. Mauri (2008: 402-403). 


\section{Conclusiones}

En resumen, las bases del estatuto de los empleados públicos vigentes reguladas en el EBEP mejoran considerablemente la anterior regulación y ofrecen respuestas a problemas que se habían ido poniendo de manifiesto. Las mejores respuestas serían las siguientes:

1. ${ }^{\circ}$ El EBEP realiza una distinción más adecuada que su antecesora entre las bases del régimen estatutario de los funcionarios públicos y la regulación del estatuto de los funcionarios y empleados públicos al servicio de la Administración General del Estado.

2. El reconocimiento legal explícito de la negociación colectiva conjunta para personal laboral y funcionarial.

3. ${ }^{\circ}$ El reconocimiento de la legitimación negocial de las asociaciones de para la negociación de ámbito supramunicipal, es decir, para una negociación que englobe las condiciones de trabajo del conjunto del personal al servicio de las diferentes entidades locales del estado o de una concreta comunidad autónoma.

4. ${ }^{\circ}$ La previsión de que se puedan constituir mesas sectoriales por decisión de las generales, también en el ámbito de las entidades locales.

5. ${ }^{\circ}$ La configuración de las Mesas de Negociación como comisiones negociadoras con reglas que promueven una relación efectiva entre organizaciones sindicales representantes y las personas físicas representadas, al establecer expresamente que las mesas quedarán válidamente constituidas cuando las organizaciones sindicales que participen en ellas representen, como mínimo, la mayoría absoluta de los miembros de los órganos unitarios de representación en el ámbito de que se trate y a través de la introducción de reglas concretas sobre la composición numérica de dichas comisiones.

6. ${ }^{\circ}$ El reconocimiento de materias y condiciones de trabajo comunes a los públicos y de la necesidad de que esas materias se regulen y se negocien de manera conjunta.

No obstante, sigue habiendo puntos oscuros:

1. El tenor literal de la norma parece indicar que sigue siendo preceptiva la constitución de mesas de negociación en cada administración territorial, entidades locales incluidas y con independencia de su dimensión. Las Mesas de Negociación a constituir en cada ámbito territorial se duplican al exigir la ley la constitución de Mesas de Negociación para las materias comunes al personal funcionario y laboral y otras, con diferente composición, a los efectos de la negociación colectiva de los funcionarios públicos. 
2. No se excepciona para las entidades locales de pequeña dimensión la falta de legitimación negocial de las Juntas de Personal.

3. ${ }^{\circ}$ Si bien se reconoce la legitimación de las asociaciones de municipios para negociar en un ámbito supramunicipal, no se profundiza en las reglas de relación a establecer entre esa unidad de negociación supramunicipal y las correspondientes comisiones negociadores a constituir en cada entidad local, más allá de una referencia básica a la posibilidad de adherirse a los acuerdos alcanzados en un ámbito supramunicipal.

4. ${ }^{\circ}$ El artículo 38.9 EBEP deja claro que la estructura de la negociación colectiva las administraciones públicas puede ser objeto de negociación y que, por lo tanto, se trata de una materia disponible, pero no queda claro el alcance de esa disponibilidad.

5. Las materias comunes a personal funcionario y laboral no se agotan en el incremento global de las retribuciones a incluir en la ley de presupuestos generales del Estado, pero no resulta fácil concretar ese concepto jurídico indeterminado, ni discernir el grado de imperatividad en dicha regulación. La opción de favorecer la determinación conjunta de materias y condiciones de trabajo, sean o no comunes o cuenten o no con una regulación legal homogénea, que sería la opción de los poderes públicos vascos, cuenta con defensores y detractores en la doctrina científica.

6. ${ }^{\circ}$ La impugnación judicial de los acuerdos fruto de la negociación colectiva conjunta sigue siendo una cuestión abierta.

\section{Bibliografía}

Alonso olea, Manuel y Casas Baamonde, María Emilia (2002): Derecho del Trabajo, Madrid, Civitas.

CANTERo Martínez, Josefa (2001): El empleo público: entre estatuto funcionarial y contrato laboral, Madrid, Marcial Pons.

Del Rey Guanter, Salvador (1988): Comentarios a la ley de órganos de representación, determinación de las condiciones de trabajo y participación del personal al servicio de las administraciones públicas, Madrid, MAP.

- (1989): «Evolución general y problemática fundamental de las relaciones colectivas en la Función Pública», en AA.VV., Seminario sobre relaciones colectivas en la Función Pública, Sevilla, IAAP.

Fernández Domínguez, Juan José y Rodríguez Escanciano, Susana (1996): La negociación colectiva de los funcionarios públicos, Barcelona, Cedecs.

JimÉnez Asensio, Rafael (2004): «El reparto de competencias entre el Estado y las Comunidades Autónomas en materia de función pública», Revista Vasca de Administración Pública, 69, 129-160.

López GANDIA (2008): «La negociación colectiva de los funcionarios públicos tras el Estatuto básico", en AA.VV. XIX Congreso Nacional de Derecho del Trabajo y de la Seguridad Social, El Estatuto Básico del Empleado Público, Badajoz. 
Marín Alonso, M. ${ }^{a}$ Inmaculada (1999): La negociación colectiva conjunta del personal laboral y funcionarial en la administración pública: los acuerdos mixtos, Albacete, Comares.

- (2006): «La reforma de la negociación colectiva en las Administraciones públicas: la mesa general unitaria y las mesas generales conjuntas (a propósito de la Ley 21/2006 de reforma de la Ley 9/1987, de órganos de representación, determinación de las condiciones de trabajo y participación del personal al servicio de las Administraciones públicas)», Aranzadi Social, 5, 1033-1052.

- (2013): «La progresiva desprotección del trabajador público frente al trabajador común: de las singularidades de la regulación individual y colectiva al desmantelamiento del derecho a la negociación colectiva», Relaciones Laborales, 4, 29-45.

Martínez Gayoso, M. ${ }^{a}$ Nieves (1999): «Participación en la determinación de las condiciones de trabajo", en AA.VV. Derecho Social Vasco, Oñati, IVAP, 473-509.

- (2002): El derecho a la negociación colectiva de los funcionarios públicos en la Constitución, Bilbao, UPV.

- (2002): Las comisiones de seguimiento de Pactos y Acuerdos en la Función Pública, Ońati, IVAP.

- (2003): dir. La negociación colectiva de las condiciones de trabajo de los empleados públicos al servicio de las Administraciones públicas vascas, Madrid, Dykinson.

Mauri Majós, Joan (1995): «Problemas de la representación sindical y la negociación colectiva en la función pública. Convergencias y divergencias con el empleo privado», Documentación Administrativa, 241-242.

- (2008): «La negociación colectiva (arts. 31 a 38)» en Del Rey Guanter, Salvador (dir.), Comentarios al Estatuto Básico del Empleado Público, Madrid, La Ley, 371-432.

Montoro Chiner, María Jesús, (1995): «Para la reforma del empleo público: nueve proposiciones", Revista de Administración pública, 136, 179-200.

Orsi Bataglini, Andrea (1993): «Fonti normative e regime giuridico del rapporto d'impiego con enti pubblici», Giornale di Diritto del Lavoro e di Relazioni Insdustriali, 59-60, 1993.

Roqueta Buj, R. (1996): La negociación colectiva en la Función Pública, Valencia, Tirant lo Blanch.

- (2008): «La negociación colectiva conjunta del personal funcionario y laboral de las Administraciones públicas. Las materias objeto de negociación colectiva en la mesa de materias comunes. El papel del comité de empresa en la negociación de la mesa de materias comunes.», Seminari sobre relacions collectives, Federació de Municipis de Catalunya, 1-11. 